\section{O13 (continued)}

also be used by policymakers to create best practice guidelines and policies to "grow" well-integrated school gardens. Funding: None.

\section{Healthy Being - Improving Nutrition Practices Among Children and Teens Through} Art and Games

Eileen Rivera, BS, erivera@care.org, CARE Guatemala, 22 Calle 15-25 Zona 13, 1013, Guatemala; M. Lopez, BS, CARE Guatemala; B. Witcher Cottrell, PhD, CARE USA

Objective: Healthy Being (HB) focuses on improving the nutritional status of 4,310 children (6-12 years) through art and games.

Target Audience: Approximately 39,000 indirect beneficiaries -parents, teachers and local stakeholders- from two communities in Chimaltenango will be reached and trained, in partnership with local theater groups, the Ministry of Education, and Municipal Authorities, supported by the FEMSA Foundation.

Theory, Prior Research, Rationale: Cardenas Silva, 2006 and J. Barojas, 1999, have advocated using games and art as attractive teaching resources that stimulate participation, awareness, self -knowledge and learning. Guatemala has the highest prevalence of chronic child malnutrition among elementary school children and adolescents in Latin America, ranking third worldwide. The province of Chimaltenango has been classified as a very high risk region with $53.9 \%$ chronic malnutrition.

Description: HB implements nutrition improvement through an innovative approach based on theatre, song, poetry and drawing. HB staff has scheduled six monthly training sessions for parents and teachers in school grounds during regular hours. Additionally, one hundred HB trained local teens will deliver culturally appropriate food and nutrition security messages through theatre, creative games and artistic competitions to create awareness of positive nutritional practices increasing water, animal source, fruits and vegetable consumption.

Evaluation: The messages were identified in the baseline and formative research. Sustainability and scale up will be achieved through partnerships with schools and influential community stakeholders. Teachers and parents are supporting the project.

Conclusion: The project baseline revealed that although children, teens and parents have basic nutrition knowledge, their daily meals lack vegetables, fruit, protein and clean water. Funding: FEMSA, Coca-Cola.

\section{Process Evaluation Measures Effectively Assess Fidelity of Fuel for Fun Classroom Lessons}

Jessica Clifford, MS, RD, MA, jessica.haas@colostate.edu, Colorado State University, Department Food Science Human Nutrition, 1571 Campus Delivery, Fort Collins, CO 80523; S. Smith, MS, RD; R. Brandenburg, BS;

B. Lohse, PhD, RD, Pennsylvania State University; Leslie Cunningham-Sabo, PhD, RD, Colorado State University
Objective: To assess fidelity of Fuel for Fun cooking and tasting classroom lessons in year 1 of program intervention using 3 process evaluation measures.

Design, Setting and Participants: Process evaluation conducted in year 1 of Fuel for Fun intervention, a school-based participatory research program delivered in 8 schools in 22 th grade classrooms. Intervention includes 5 cooking and 5 tasting lessons in classrooms.

Outcome Measures and Analysis: Classroom lesson debriefing form completed by educator after each lesson; tested classroom lesson observation form completed by evaluation personnel; and weekly team meeting transcripts. Assessed fidelity to lesson components with checklist (highest possible score 21 cooking; 17 tasting), classroom management $(3=$ no problems, $1=$ major problems), and student engagement ( $4=$ actively involved, $1=$ uninterested) using descriptive statistics and thematic analysis of observation comments.

Results: 214 classroom lesson debriefing forms, 14 classroom lesson observation forms (5 cooking, 9 tasting), and compiled meeting transcripts were completed in year 1 of intervention. Mean scores were 18.6 and 15.2 for cooking and tasting lessons components, 3.0 for classroom management, and 3.8 for student engagement. Thematic analysis revealed 3 themes. Keeping children as engaged as possible at all times with hands-on- activity is a priority. Reinforcement of student behavioral expectations with every lesson was beneficial, and educator flexibility is critical when working with teachers and students in the classroom.

Conclusions and Implications: Classroom lesson fidelity was maintained while remaining flexible to the classroom situation. Process evaluation measures were valuable in assessing lesson fidelity in year 1 and in providing direction for future intervention implementation.

Funding: NIFA.

\section{Improving Nutrition Knowledge, Attitude and Behavior of Selected Filipino Schoolchildren in the Healthy Kids Program} Julieta Dorado, MS, juliebdorado@yahoo.com, Food and Nutrition Research Institute-Department of Science and Technology, DOST Compound, Gen. Santos Avenue, Bicutan, Taguig City, Metro Manila 1633, Phillipines; G. Azana; R. Viajar MS; M. Capanzana, PhD

Objective: This study evaluated the effects of a schoolbased nutrition education intervention (Healthy Kids Program) on the knowledge, attitude and behaviour of schoolchildren.

Design, Setting and Participants: The experimental design with intervention and non-intervention groups was used. The project was conducted in two public elementary schools in the rural town of Bulacan in the Philippines among 200 schoolchildren aged 9-10 year old grouped into intervention $(n=100)$ and non-intervention (100). Two periods of data collections were conducted in both 